\author{
WiOLETA ZGLICZYŃSKA* \\ Uniwersytet Mikołaja Kopernika w Toruniu
}

\title{
PORÓWNANIE SKŁADKI NETTO ZE SKŁADKĄ BRUTTO W UBEZPIECZENIACH NA ŻYCIE
}

Słowa kluczowe: składka netto, ubezpieczenia.

\begin{abstract}
Abstrakt: Zakłady ubezpieczeniowe mają swoje metody na wyliczenie wysokości składki ubezpieczeniowej. W artykule składka netto została obliczona za pomocą funkcji komutacyjnych. Obliczenia opierają się na tablicach trwania życia. Prawdopodobieństwo śmierci jest ściśle związane z wiekiem osoby ubezpieczonej. Im starsza osoba, tym wyższe ryzyko. Dlatego wysokość składki jest uzależniona od wieku ubezpieczonego. Na jej wielkość wpływają jeszcze inne czynniki. Osoby chore, uprawiające sporty ekstremalne, wykonujące ryzykowny zawód są bardziej narażone na śmierć. Teoretycznie wyliczona składka uwzględnia wszystkie przyczyny śmierci. Porównanie matematycznie obliczonej składki netto i składek brutto oferowanych przez zakłady ubezpieczeniowe ma na celu uświadomienie, jak wysoka jest cena ryzyka oraz kosztów związanych z ubezpieczeniem. Na składki obejmujące wszystkie możliwości utraty życia niewiele osób mogłoby sobie pozwolić ze względu na zbyt wysoką cenę. Obniżając składkę, trzeba zmniejszyć ryzyko ubezpieczeniowe. Nieunikniona w tym przypadku jest segmentacja rynku i wyeliminowanie największego ryzyka. Osoby nieuleczalnie chore zostają wykluczone z możliwości zakupu ubezpieczenia. Natomiast ludziom uprawiającym sporty ekstremalne zakład może zaproponować wyższą składkę lub ubezpieczenie wykluczające śmierć spowodowaną wykonywanym hobby. Na podstawie powyższych wniosków zakłady ubezpieczeniowe nie mogą ubezpieczonych traktować homogenicznie, ale powinny być otwarte na tworzenie indywidualnych ofert dostosowanych do klienta, w ten sposób zmniejszając ponoszone ryzyko i wysokość składki ubezpieczeniowej, a to powoduje, że są bardziej konkurencyjne na rynku.
\end{abstract}

Data wpłynięcia: 22.11.2012; data zaakceptowania: 25.02.2013.

* Dane kontaktowe: w.zgliczynska@gmail.com, Wydział Nauk Ekonomicznych i Zarządzania, Uniwersytet Mikołaja Kopernika, ul. Gagarina 13a, 87-100 Toruń. 


\section{THE COMPARISON OF NET PREMIUM TO GROSS PREMIUM VOLUME OF LIFE INSURANCE}

Key words: insurance, net premiums.

Abstract: Insurance companies have their own methods concerning the calculation of premiums' costs. In the article, a net premium was counted with the use of commutation functions. The calculation is based on life tables. The death probability is inextricably connected with the age of an insured party. It is affected by other factors as well. People, who suffer from diseases, do extreme sports or have a risky job are more exposed to death. Theoretically, the calculated insurance premium takes all the causes of death into consideration. The mathematical comparison of the calculated net premium with the gross premiums proposed by insurance companies aims at making people aware of the fact how high is the price of risk and the costs of insurance. If people are offered premiums encompassing all the probable causes of death, not many of them can afford paying premiums because of too high price. While decreasing a premium, it is necessary to lower insurance risk. In this case, the reduction of the largest risk and market segmentation is unavoidable. People with incurable diseases are excluded from having an insurance. A company can offer a higher premium or insurance excluding death caused by a hobby to people, who are fond of extreme sports. On the basis of the above-mentioned conclusions, insurance companies cannot treat the insured parties in a homogeneous way, but they should be open to create individual offers adjusted to a customer. It makes them more competitive on the market.

Translated by Wioleta Zgliczyńska

\section{WSTĘP}

Ubezpieczenia na życie są długoterminowe, czyli składki płacone przez ubezpieczających przez długi okres pozostają do dyspozycji zakładów ubezpieczeń, które ich pewną część, tzw. rezerwy, inwestują na rynku kapitałowo-pieniężnym (Kowalczyk i in. 2006). Inwestowanie nie jest najważniejszym zadaniem zakładu ubezpieczeń, podstawą poprawnego funkcjonowania jest odpowiednie obliczenie wysokości składki ubezpieczeniowej, ale jest to problem bardzo obszerny i skomplikowany. Nieprawidłowe obliczenie składki może doprowadzić do niebagatelnych konsekwencji, np. niepełnych wypłat świadczeń lub do bankructwa zakładu ubezpieczeń. „Ubezpieczenia na życie stanowią ciągle jedną z najbardziej efektywnych form zabezpieczenia przyszłości sobie oraz swojej rodzinie" (Śliwiński 2012: 14), dlatego tak ważne jest poprawne obliczenie składki.

W ubezpieczeniach na życie istotną rolę odgrywa ryzyko śmierci, której miarą jest prawdopodobieństwo śmierci osoby w danym wieku. Wysokość ryzyka śmierci determinuje poziom składek ubezpieczeniowych (Śliwiński 
2012: 16). Część składki pokrywająca koszty ryzyka ponoszonego przez zakłady ubezpieczeń nazywa się składką netto. Sumując wysokość składki netto i dodatkowe koszty działalności ubezpieczeniowej, otrzymuje się składkę brutto, czyli ostateczną cenę usługi ubezpieczeniowej.

Celem artykułu jest porównanie wysokości teoretycznie wyliczonej składki netto ze składką brutto, oferowaną przez zakłady ubezpieczeniowe funkcjonujące na polskim rynku. Uzyskane wyniki opierają się na tablicach trwania życia z 2011 r., udostępnionych na stronie Głównego Urzędu Statystycznego. Na ich podstawie została obliczona wysokość składki netto dla poszczególnych osób w wieku z przedziału [0,100], przy uwzględnieniu, że obliczaniu wysokości składki zawsze towarzyszy pewne ryzyko, jednak za pomocą matematycznych obliczeń możliwe jest jego ograniczenie.

\section{WPEYW RYZYKA NA SKEADKĘ UBEZPIECZENIOWĄ}

Ryzyko to pojęcie fundamentalne dla ubezpieczeń. Poszukiwanie zabezpieczenia przyczyniło się do rozwoju teorii ubezpieczeń. Przez rozwój takich nauk, jak statystyka i teoria prawdopodobieństwa, niepewność związana z ryzykiem została zminimalizowana. Powstało wiele definicji ryzyka, lecz żadna z nich do końca nie odzwierciedla wszystkich jego aspektów. Rozpatrując ryzyko ubezpieczeniowe, należy przyjrzeć się dokładniej dwóm charakterystycznym podejściom do tego zagadnienia. Pierwsze to ujęcie ekonomiczne, które rozważa ryzyko pod względem niebezpieczeństw, postrzeganych jako przyczyna realnych zdarzeń, faktów lub zjawisk społeczno-ekonomicznych. Odmienne podejście zaproponował Witold Warkałła w 1971 r., który ryzyko rozpatrywał od strony skutków wystąpienia niebezpieczeństw. Jest to dorobek polskiej nauki prawa ubezpieczeniowego. W celu utworzenia pełnej definicji ryzyka należy analizować oba podejścia jednocześnie (Śliwiński 2012: 33).

Komisja ds. Terminologii Ubezpieczeniowej USA w 1966 r. opublikowała dwa oficjalne określenia. W pierwszym stwierdzono, że ryzyko to niepewność nastąpienia zdarzenia przy istnieniu dwóch lub więcej możliwości. Druga definicja jest wykorzystywana głównie w ubezpieczeniach, określa ryzyko jako ubezpieczoną osobę lub przedmiot (Biernacki 2005: 5). Tomasz Michalski krytykuje tę definicję, twierdząc, że ,jest ona określeniem wielce użytecznym w znaczeniu komunikatywnym, lecz ma niewielką wartość poznawczą". Utożsamianie ryzyka z przedmiotem ubezpieczenia zawęża to zagadnienie. $\mathrm{W}$ ubezpieczeniach na życie tym przedmiotem jest osoba, której nie należy traktować 
jako źródło ryzyka, ale jako przedmiot narażony na jego wystąpienie (Śliwiński 2012: 41).

Ważny jest fakt, że jeżeli ryzyko rozumie się jako prawdopodobieństwo szansy wystąpienia straty, należy przyjąć za szansę zajścia zdarzenia przedział między 0 a 1, odrzucając skrajne przypadki, ponieważ gdy szansa wystąpienia straty jest równa 1, wtedy zajście szkody jest pewne, a ryzyko nie występuje, co prowadzi do sprzeczności definicji. „Odpowiedni stosunek do ryzyka stanowi podstawę zarządzania nim, czyli racjonalnego sterowania elementami ryzyka, mającego na celu uniknięcie lub ograniczenie finansowych skutków zdarzeń losowych" (Rurka 2005).

Ryzyko w ubezpieczeniach na życie ma specyficzny charakter. Wystąpienia śmierci nie należy traktować jako ryzyka. Śmierć jest nieuniknionym zdarzeniem w życiu każdego człowieka. Nie można przewidzieć śmierci jednostki, ale jest to możliwe w badaniu większej populacji. Poziom ryzyka wpływa na wysokość składki ubezpieczeniowej. „Cechą charakterystyczną ryzyka śmierci jest to, że stopień jego realizacji rośnie wraz z wiekiem osoby ubezpieczonej" (Śliwiński 2012: 50). Wspomniany wyżej wiek, przebyte choroby i tryb życia (sporty ekstremalne) zwiększają ryzyko śmierci i powodują wyższe składki ubezpieczeniowe.

Rynek ubezpieczeniowy specjalizuje się w handlu ryzykiem. Towarzystwa ubezpieczeniowe przyjmą za odpowiednią cenę, która zostanie określona jako składka w umowie ubezpieczeniowej, prawie wszystkie ryzyka, z wyjątkiem tzw. nieubezpieczanych, związanych np. z wybuchem wojny, strajkami (w tych przypadkach państwo ma rolę ubezpieczyciela) (Maleszka 2000). Analiza ryzyka jest dokonywana przez przedstawicieli zakładu ubezpieczeń, tzw. underwriterów. Niestety, nie każde ryzyko jest łatwe do wykrycia, np. hazard moralny. Przykładem hazardu moralnego może być zorganizowanie przez osoby upoważnione, które zostały wymienione w polisie, działań powodujących śmierć osoby ubezpieczonej w celu uzyskania własnych korzyści.

\section{PODEJŚCIE MATEMATYCZNE I STATYSTYCZNE DO RYZYKA ŚMIERCI}

Prawdopodobieństwo śmierci to jeden z podstawowych czynników, który wpływa na wielkość składek ubezpieczeniowych. W praktyce obliczane jest na podstawie badań empirycznych na pewnej próbie, tzw. kohorcie, czyli grupie ludzi będących w tym samym wieku, obserwowanej aż do śmierci (Śliwiński 2012; 52). Informacje dotyczące prawdopodobieństw zgonów znajdują się 
w tzw. tablicach trwania życia, które są tworzone na podstawie danych empirycznych dotyczących umieralności ludzi w pewnym wieku. Autorem pierwszych tablic trwania życia, które zostały opublikowane w 1693 r., był angielski astronom E. Halley. Tablice te powstały na podstawie danych demograficznych ludności z Wrocławia, zgromadzonych przez wrocławskiego pastora Kacpra Neumanna i przesłanych do Anglii. Na stronie Głównego Urzędu Statystycznego co roku publikowane są tablice trwania życia. Przykład takiej tablicy przedstawia poniższa tabela.

Tabela 1. Tablice trwania życia 2011

\begin{tabular}{|c|c|c|c|c|c|c|}
\hline \multirow{2}{*}{ Wiek } & \multirow{2}{*}{$\begin{array}{c}\text { Liczba } \\
\text { dożywających }\end{array}$} & \multirow{2}{*}{$\begin{array}{l}\text { Prawdopodo- } \\
\text { bieństwo } \\
\text { zgonu }\end{array}$} & \multirow{2}{*}{$\begin{array}{c}\text { Liczba } \\
\text { zmarłych }\end{array}$} & \multicolumn{2}{|c|}{ Ludność stacjonarna } & \multirow{2}{*}{$\begin{array}{l}\text { Przeciętne } \\
\text { dalsze } \\
\text { trwanie życia }\end{array}$} \\
\hline & & & & w wieku $\mathrm{x}$ & skumulowane & \\
\hline$x$ & $I_{x}$ & $q_{x}$ & $d_{x}$ & $\mathrm{~L}_{\mathrm{x}}$ & $T_{x}$ & $e_{x}$ \\
\hline \multicolumn{7}{|c|}{ Mężczyźni ogółem } \\
\hline 0 & 100000 & 0,00508 & 508 & 99556 & 7244329 & 72,44 \\
\hline 1 & 99492 & 0,00031 & 31 & 99477 & 7144773 & 71,81 \\
\hline 2 & 99462 & 0,00024 & 24 & 99450 & 7045296 & 70,83 \\
\hline 3 & 99438 & 0,00019 & 19 & 99429 & 6945846 & 69,85 \\
\hline 4 & 99419 & 0,00017 & 17 & 99411 & 6846418 & 68,86 \\
\hline
\end{tabular}

Źródło: opracowanie własne na podstawie danych GUS, http://www.stat.gov.pl/gus/5840_ 4721_PLK_HTML.htm.

Wiek oznaczono przez $x$ i ograniczono do przedziału $[0,100]$. Ta informacja znajduje się w pierwszej kolumnie tablic trwania życia. Kolejna kolumna z nagłówkiem $l_{x,}$ oznacza przeciętną liczbę osób, które dożyły wieku $x$ spośród wybranej bazowej liczby $l_{0}=100000$ noworodków. Przez $d_{x}$ rozumie się przeciętną liczbę zgonów w przedziale wieku od $x$ do $x+1$, czyli (Śliwiński 2012: 62):

$$
d_{x}=l_{x}-l_{x+1}
$$

Podstawą w teorii ubezpieczeń na życie jest funkcja przeżycia (ang. survival function) S(x), jest to prawdopodobieństwo zdarzenia, że noworodek, który został losowo wybrany z populacji, dożyje wieku $x$ lat. Przez $F(x)$ oznacza się dystrybuantę długości życia noworodka, którą można wyliczyć ze wzoru (Śliwiński 2012: 53): 


$$
F(x)=P(X \leq x), x \geq 0
$$

gdzie $X$ oznacza czas trwania życia. Oznacza to, że zmienna losowa $X$ przyjmuje wartości nie większe niż $x$, czyli śmierć noworodka nastąpiła w przedziale wieku $[0, x]$. Pomiędzy funkcją przeżycia a dystrybuantą zachodzi istotna zależność (Słomiński 2010: 25):

$$
S(x)=1-F(x), x \geq 0 .
$$

Informacje dotyczące prawdopodobieństwa zgonów wykorzystywane w praktyce ubezpieczeniowej są tworzone na podstawie badań empirycznych przeprowadzanych na dużej populacji z przeszłości. Oznacza to, że jeśli przeprowadzając badanie panelowe na próbie o liczbie $N$ osób w tym samym wieku, stwierdzono w przyszłym roku śmierć $n$ ludzi, to przybliżone prawdopodobieństwo zgonu wyniesie $n / N$. Zakłada się, że dzięki wynikom uzyskanym w badaniach z przeszłości można prognozować prawdopodobieństwo zgonów w przyszłości (Śliwiński 2012: 57).

Zmienna losowa $T(x)$ oznacza przyszły czas życia (ang. future lifetime) osoby w wieku $x$, określa się go następująco (Słomiński 2010: 25):

$$
T(x)=X-x \text { dla } X \geq x,
$$

łatwo zauważyć, że

$$
T(0)=X \text {. }
$$

Prawdopodobieństwo zdarzenia, że osoba w wieku x przeżyje więcej czasu niż $t$ (Słomiński 2010: 26):

$$
{ }_{t} p_{x}=P(T(x)>t) .
$$

Natomiast prawdopodobieństwo zgonu osoby w wieku x przed upływem czasu t przedstawia się w postaci (Słomiński 2010: 26):

$$
\left.{ }_{t} q_{x}=P(T x) \leq t\right)=1-{ }_{t} p_{x} .
$$


Zachodzi oczywista równość

$$
{ }_{t} p_{x}+{ }_{t} q_{x}=1
$$

Przez symbol $p_{x}$ rozumie się prawdopodobieństwo, że osoba będąca w wieku $x$ przeżyje rok, natomiast symbol $q_{x}$ oznacza prawdopodobieństwo, że osoba w wieku $x$ umrze w ciągu roku.

Prawdopodobieństwo, że osoba w wieku $x$ lat przeżyje $t$ lat i umrze w okresie następnych $u$ lat, wyraża się wzorem (Śliwiński 2012: 57):

$$
{ }_{t \mid u} q_{x}=P(t<T(x) \leq t+u)={ }_{t} p_{x}-{ }_{t+u} p_{x}
$$

\section{SKŁADKA NETTO $W$ UBEZPIECZENIACH NA ŻYCIE}

W ubezpieczeniach na życie ubezpieczyciel jest zobowiązany do wypłacenia świadczenia po śmierci ubezpieczonego. Najczęściej jest ono wypłacane na koniec roku, w którym nastąpił zgon ubezpieczonego. Wysokość wypłaconej sumy zależy od wysokości płaconej (często miesięcznej) składki brutto, którą tworzy składka netto (składka czysta) i dodatkowe koszty poniesione przez zakład ubezpieczeń obejmujące koszty zawarcia umowy i prowadzenia ubezpieczenia.

Składka czysta jest częścią składki przeznaczoną na wypłatę świadczenia. Jest to udział ubezpieczonego w funduszu, z którego są wypłacane świadczenia. Obliczanie składki netto jest złożoną i skomplikowaną procedurą. Jej wysokość zależy od ryzyka objętego ubezpieczeniem. Istotnym założeniem przy obliczaniu składki netto jest przyjęcie, że w okresie ubezpieczenia techniczna stopa zwrotu $i$ (przyjmowana przez zakłady ubezpieczeniowe od 3\% do 5\%) jest stała, a odpowiadający jej czynnik dyskontujący (ang. discount factor) (Słomiński 2010: 9) to:

$$
v=\frac{1}{i+1}
$$

Dyskontowanie umożliwia zakładom ubezpieczeniowym zastosowanie zasady równości. Oznacza to, że przeciętne składki ubezpieczonych powinny pokryć kwotę wydatków, towarzyszących w przyszłości świadczeniom. Przy złych kalkulacjach ubezpieczyciel może ponieść stratę. Pojęcie straty (netto) ubezpie- 
czyciela oznaczamy symbolem $L$, jest to różnica wartości przyszłych świadczeń i przyszłych składek, które zostaną wpłacone przez ubezpieczonego.

Zasadę równości łatwo teraz zdefiniować (Słomiński 2010: 57):

$$
E(L)=0 \text {, }
$$

Ubezpieczony kupuje polisę $\mathrm{w}$ wieku $x$ lat. Umiera $\mathrm{w}$ wieku $T(x)+x$. Dla danej zmiennej losowej $T(x)$ definiujemy (Słomiński 2010: 31):

$$
K(x)=[T(x)]
$$

gdzie [] oznacza część całkowitą, $K(x)$ nazywamy obciętym czasem życia (ang. curtate furture lifetime).

Rysunek 1. Ubezpieczenie bezterminowe na życie

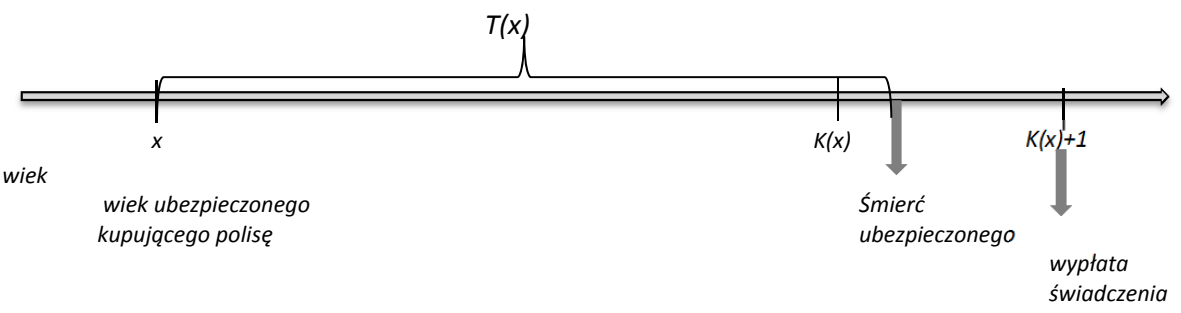

Źr ó d ł o : opracowanie własne na podstawie: Skałba 1999: 36.

Z rysunku 1 wynika, że śmierć ubezpieczonego następuje między rokiem $K(x)$ a $K(x)+1$. W ubezpieczeniach płatnych na koniec roku śmierci wypłata następuje $\mathrm{w}$ chwili $x+K(x)+1$. Dla ułatwienia rachunków zakłada się, że suma ubezpieczenia w chwili $t$ oznaczana przez $b_{t^{\prime}}$ nazywana funkcją korzyści (ang. benefit function), wynosi 1. Jest to tzw. przypadek znormalizowany.

Niech $k$ oznacza liczbę lat, które pozostały do przeżycia osobie w wieku $x$, wtedy obecna wartość polisy wynosi

$$
Z=z_{k+1}=b_{k+1} v^{k+1}=v^{k+1} .
$$

Jednorazową składkę netto oznaczamy symbolem $A_{x^{\prime}}$. Obliczana jest jako wartość oczekiwana zmiennej losowej $Z$. Stąd 


$$
A_{x}=E(Z)=E\left(z_{k+1}\right)=E\left(v_{k+1}\right)=\sum_{k=0}^{\infty} v_{k+1} P(K(x)=k)=\sum_{k=0}^{\infty} v_{k+1} p_{x} q_{x+k}
$$

gdzie $P(K(x)=k)$ jest funkcją prawdopodobieństwa zmiennej $K(x)$.

Ważną rolę przy wyznaczaniu wielkości aktuarialnych odgrywają liczby komutacyjne, które wyrażają się wzorami (Kowalczyk i in. 2006: 135):

$$
D_{x}=v^{x} l_{x}
$$

gdzie $D_{x}$ - zdyskontowana liczba osób, które osiągnęły $x$ lat,

$$
C_{x}=D_{x} v q_{x}=v^{x+1} d_{x}
$$

gdzie $C_{x}$ - zdyskontowana liczba zgonów osób w wieku $x$ lat.

Zatem

$$
M_{x}=\sum_{k=0}^{\infty} C_{x+k}=\sum_{k=0}^{\infty} v^{x+k+1} d_{x+k}
$$

oraz

$$
N_{x}=\sum_{k=0}^{\infty} D_{x+k}=\sum_{k=0}^{\infty} v^{x+k} l_{x+k}
$$

W praktyce sumowanie w powyższych wzorach odbywa się nie do nieskończoności, lecz do maksymalnego wieku $w$ objętego w tablicach trwania życia, zatem (Śliwiński 2012: 138)

$$
M_{x}=\sum_{k=0}^{w-x} C_{x+k}
$$

oraz

$$
N_{x}=\sum_{k=0}^{w-x} D_{x+k}
$$


Na podstawie powyższych wzorów jednorazową składkę netto w bezterminowym ubezpieczeniu na życie można zdefiniować wzorem (Kowalczyk i in. 2006: 136):

$$
A_{x}=\frac{M_{x}}{D_{x}} .
$$

Proces obliczania składki netto jest związany z rachunkiem rent. Renta odgrywa ważną rolę $w$ ubezpieczeniach, ponieważ „produkty ubezpieczeniowe są kupowane zazwyczaj za pomocą ciągu płatności, tj. składek ubezpieczeniowych, a nie za pomocą płatności jednorazowych" (Skałba 1999: 61). Rentę traktuje się jako wspomniany wcześniej ciąg płatności okresowych w równych odstępach czasu. Wyróżnia się wiele rodzajów rent. Jedną z nich jest renta życiowa bezterminowa, jest ona ciągiem płatności okresowych, które przestają być wypłacane w chwili śmierci rentobiorcy. Na potrzeby artykułu zostanie podany jedynie wzór na obliczanie renty życiowej płatnej na początku roku, bez zagłębiania się $\mathrm{w}$ istotę rent.

Wykorzystując funkcje komutacyjne, obecną wartość płatności można wyrazić wzorem (Śliwiński 2012: 136):

$$
\ddot{a}_{x}=\frac{N_{x}}{D_{x}} \text {. }
$$

W praktyce składki ubezpieczeń wpływają w okresach rocznych, kwartalnych, miesięcznych. Przez $P_{x}$ oznacza się jednakową roczną składkę netto płatną w ciągu całego życia. Ciąg składek jest traktowany jako opisana wcześniej renta życiowa, dzięki czemu jednorazową składkę netto można zapisać następująco (Kowalczyk i in. 2006: 142):

$$
A_{x}=\ddot{a}_{x} P_{x} .
$$

Stosując przekształcenia i liczby komutacyjne, powyższy wzór można zapisać jako (Śliwiński 2012: 139):

$$
P_{x}=\frac{M_{x}}{N_{x}} .
$$

Obliczona w ten sposób składka odpowiada świadczeniu w wysokości 1 zł wypłaconemu na koniec roku, w którym nastąpił zgon osoby ubezpieczonej.

W poniższej tabeli zostały umieszczone składki netto przy polisie równej 150 tys. zł oddzielnie dla kobiet i mężczyzn. Następnie uzyskane wyniki zosta- 
ły porównane z proponowaną przez zakład ubezpieczeniowy funkcjonujący na polskim rynku składką brutto dla osób w różnym wieku.

Tabela 2. Porównanie składki netto ze składką brutto w ubezpieczeniach na życie

\begin{tabular}{|c|c|c|c|c|}
\hline \multirow{2}{*}{ Wiek } & \multicolumn{2}{|c|}{ Kobiety } & \multicolumn{2}{|c|}{ Mężczyźni } \\
\hline & składka netto & $\begin{array}{c}\text { oferta } \\
\text { zakładu ubezpieczeń }\end{array}$ & składka netto & $\begin{array}{c}\text { oferta } \\
\text { zakładu ubezpieczeń }\end{array}$ \\
\hline 25 & $601,66 \mathrm{zł}$ & $1260,00 \mathrm{zł}$ & $994,07 \mathrm{zł}$ & $1260,00 \mathrm{z \dagger}$ \\
\hline 35 & $999,82 \mathrm{zł}$ & $1260,00 \mathrm{zł}$ & $1625,23 \mathrm{zł}$ & $1260,00 \mathrm{z} \nmid$ \\
\hline 45 & $1679,04 \mathrm{zł}$ & $1260,00 \mathrm{z} \nmid$ & $2694,26 \mathrm{z \dagger}$ & $1260,00 \mathrm{z} \nmid$ \\
\hline 55 & $2832,35 \mathrm{zł}$ & $2430,00 \mathrm{zł}$ & $4425,91 \mathrm{zł}$ & $2430,00 \mathrm{z} \nmid$ \\
\hline 60 & $3699,53 \mathrm{zł}$ & $2430,00 \mathrm{z} \nmid$ & $5637,94 \mathrm{zł}$ & $2430,00 \mathrm{z} \dagger$ \\
\hline 61 & $3907,09 \mathrm{zt}$ & $3600,00 \mathrm{z} \nmid$ & 5918,71 zł & $5400,00 \mathrm{zł}$ \\
\hline 62 & $4128,56 \mathrm{zł}$ & $3600,00 \mathrm{zł}$ & $6214,78 \mathrm{zł}$ & $5400,00 \mathrm{z} \nmid$ \\
\hline 63 & $4365,57 \mathrm{zł}$ & $3600,00 \mathrm{zł}$ & $6527,49 \mathrm{z} \nmid$ & $5400,00 \mathrm{zł}$ \\
\hline 64 & $4619,78 \mathrm{z} \nmid$ & $3600,00 \mathrm{zł}$ & $6858,45 \mathrm{zf}$ & $5400,00 \mathrm{zt}$ \\
\hline
\end{tabular}

Źr ó d ło : opracowanie własne na podstawie tablic trwania życia z 2011 r. ze strony Głównego Urzędu Statystycznego oraz http://www.credit-agricole.pl/klienci-indywidualni/ubezpieczenia/ubezpieczenie-na-zycie/kalkulator.

Od dnia 21 grudnia 2012 r. towarzystwa ubezpieczeniowe działające na terenie Unii Europejskiej zostały zobowiązane do naliczania takiej samej składki ubezpieczeniowej dla kobiet i mężczyzn za produkty ubezpieczeniowe. Bez względu na płeć, osoba o tych samych cechach (np. w tym samym wieku, o takim samym stanie zdrowia) zapłaci tyle samo za ten sam produkt (MEMO/11/123).

\section{ZAKOŃCZENIE}

Wysokość proponowanej przez towarzystwa ubezpieczeń składki brutto często jest niższa od matematycznie wyliczonej składki netto, ponieważ nie obejmuje ona wszystkich przyczyn śmierci osoby ubezpieczonej. Ubezpieczający przed podpisaniem polisy zapoznaje się z ogólnymi warunkami ubezpieczenia, w których są wyszczególnione zdarzenia ubezpieczeniowe upoważniające do wypłaty świadczenia, np. śmierć naturalna lub w wypadku. Natomiast jeżeli ubezpieczony umrze w wyniku samobójstwa lub nieuleczalnej choroby, uposażony 
może nie uzyskać wypłaty świadczenia. Zakłady ubezpieczeń zmniejszają w ten sposób ponoszone ryzyko i mogą obniżyć cenę ubezpieczenia w dość dużym stopniu. Według danych Krajowego Rejestru Nowotworów nowotwory zajmują drugie miejsce na liście najczęstszych przyczyn zgonów. Są one odpowiedzialne za 25\% zgonów zarówno wśród kobiet, jak i mężczyzn. Ten przykład bardzo dobrze ilustruje, jak spada ryzyko ponoszone przez zakłady ubezpieczeń, wykluczające śmierć w wyniku zachorowania na nowotwór ze zdarzeń objętych ubezpieczeniem. Towarzystwa ubezpieczeń, aby być bardziej konkurencyjne na rynku, proponują zakup dodatkowego ubezpieczenia, które gwarantuje wypłatę świadczenia, gdy śmierć nastąpi w wyniku choroby śmiertelnej.

Zmniejszając ryzyko, zakłady ubezpieczeniowe dostosowują indywidualnie ofertę ubezpieczeniową do klienta. Przed podpisaniem polisy ubezpieczający wypełnia kwestionariusz, w którym są zawarte pytania np. o przebyte choroby, uprawiane sporty ekstremalne. Dodatkowo zakłady ubezpieczeniowe kierują ubezpieczającego na badania lekarskie, po których mogą zwiększyć wysokość składki ubezpieczeniowej lub odmówić sprzedaży ubezpieczenia. Towarzystwa ubezpieczeniowe zawężają ryzyko, odmawiając przystąpienia do ubezpieczenia osobom, które np. przebywają na zwolnieniu lekarskim, w szpitalu, hospicjum. Dzięki takim ograniczeniom ryzyko ponoszone przez zakłady ubezpieczeń spada, oferty stają się konkurencyjne i przede wszystkim cenowo możliwe do zakupienia dla dużej liczby osób.

Przy obliczaniu jednorazowej składki netto ryzyko śmierci zostało proporcjonalnie rozłożone na wszystkich ludzi w badanej populacji, a badane jednostki zostały potraktowane homogenicznie. W życiu ryzyko nie rozkłada się jednakowo. Ludzie chorzy, uprawiający sporty ekstremalne czy palący papierosy mają wyższy współczynnik umieralności. Zakłady ubezpieczeniowe, aby zmniejszyć ryzyko, zlecają wykonanie badań lekarskich, przez które dokonują tzw. selekcji negatywnej (adverse selective), czyli wykluczają z badanej populacji jednostki najbardziej narażone na ryzyko. W grupie osób nieubezpieczanych są osoby śmiertelnie chore. Dzięki takiej selekcji zakłady ubezpieczeniowe mogą zmniejszyć wysokość składki ubezpieczeniowej. Segmentacja jest wymuszona przez potrzeby rynku, wysokość składki ubezpieczeniowej musi być dostosowana do portfela ubezpieczonego.

\section{LITERATURA}

Arkusz informacyjny: Unijne zasady dotyczqce ustalania wysokości składek ubezpieczeniowych niezależnie od kryterium płci (2012), Bruksela. 
Biernacki L. (2005), Ryzyko w pośrednictwie ubezpieczeniowym, WSE, Bochnia, nr 3.

Błaszczyszyn B., Rolski T. (2004), Podstawy matematyki ubezpieczeń na życie, Wydawnictwo Naukowo-Techniczne, Warszawa.

Gerber H. U. (1990), Life Insurance Mathematics, Springer, Swiss Association of Actuaries, Berlin-Zürich.

Jaworski P., Micał J. (2005), Modelowanie matematyczne $w$ finansach i ubezpieczeniach, POLTEXT, Warszawa.

Kowalczyk P., Poprawska E., Ronka-Chmielowiec W. (2006), Metody aktuarialne, Wydawnictwo Naukowe PWN, Warszawa.

Maleszka L. (2000), Zarzq̨dzanie ryzykiem w ubezpieczeniach, Akademia Ekonomiczna, Poznań.

Rurka A. (2005), Reasekuracja a zarządzanie ryzykiem ubezpieczeniowym, Studia i Materiały, Wydawnictwo Naukowe Wydziału Zarządzania UW, Warszawa.

Skałba M. (1999), Ubezpieczenia na życie, WNT, Warszawa.

Słomiński L. (2010), Podstawy matematyki ubezpieczeń, Wydział Matematyki i Informatyki UMK, Toruń.

Śliwiński A. (2012), Przestrzenne zróżnicowanie ryzyka ubezpieczeniowego a efektywność ubezpieczeń na życie, Oficyna Wydawnicza Szkoła Główna Handlowa, Warszawa.

Zakrzewska-Derylak B., Szkutnik W. (2004), Decyzyjne uwarunkowania użyteczności $i$ wiarygodności probabilistycznej w zarządzaniu ryzykiem ubezpieczeniowym, Wydawnictwo Akademii Ekonomicznej, Katowice. 
